\title{
Reversal Rate of Clustering of Cardiovascular Disease Risk Factors of Metabolic Syndrome in the General Population: The Niigata Preventive Medicine Study
}

\author{
Shinsuke Okada, ${ }^{1}$ Akiko Suzuki, ${ }^{1}$ Hiroshi Watanabe, ${ }^{1}$ Toru Watanabe, ${ }^{2}$ \\ and Yoshifusa Aizawa ${ }^{1}$ \\ ${ }^{1}$ Divisions of Endocrinology and Metabolism and Cardiology, Graduate School of Medical and Dental Science, Niigata University, \\ Niigata 951-8510, Japan \\ ${ }^{2}$ Niigata Health Foundation, Niigata 951-8581, Japan
}

Correspondence should be addressed to Yoshifusa Aizawa, aizaways@med.niigata-u.ac.jp

Received 25 August 2010; Accepted 19 October 2010

Academic Editor: Jack Adam Yanovski

Copyright (C) 2010 Shinsuke Okada et al. This is an open access article distributed under the Creative Commons Attribution License, which permits unrestricted use, distribution, and reproduction in any medium, provided the original work is properly cited.

\begin{abstract}
The reversal rate from clustering of cardiovascular disease (CVD) risk factors-components of the metabolic syndrome (MetS) is not known. Methods and Results. Among 35,534 subjects who received the annual health examinations at the NiigataHealth Foundation (Niigata, Japan), 4,911 subjects had clustering of 3 or more of the following CVD risk factors: (1) body mass index $(\mathrm{BMI}) \geq 25 \mathrm{Kg} / \mathrm{m}^{2}$, (2) blood pressure $\geq 130 \mathrm{~mm} \mathrm{Hg}$ in systolic and/or $\geq 85 \mathrm{~mm} \mathrm{Hg}$ in diastolic, (3) triglycerides $\geq 150 \mathrm{mg} / \mathrm{dL}$, (4) high-density lipoprotein cholesterol $\leq 40 \mathrm{mg} / \mathrm{dL}$ in $\mathrm{men}, \leq 50 \mathrm{mg} / \mathrm{dL}$ in women, and (5) fasting blood glucose $\geq 100 \mathrm{mg} / \mathrm{dL}$. After 5 years 1,929 subjects had a reversal of clustering (39.4\%). A reversal occurred more often in males. The subjects with a reversal of clustering had milder level of each risk factor and a smaller number of risk factors, while BMI was associated with the least chance of a reversal. Conclusion. We concluded that a reversal of clustering CVD risk factors is possible in 4/10 subjects over a 5-year period by habitual or medical interventions. Gender and each CVD risk factor affected the reversal rate adversely, and BMI was associated with the least chance of a reversal.
\end{abstract}

\section{Introduction}

Metabolic syndrome (MetS) is diagnosed as a clustering of cardiovascular disease (CVD) risk factors, including obesity, hypertension, impaired glucose metabolism, and dyslipidemia, and the diagnostic criteria have been proposed by several organizations [1-5]. MetS or clustering of CVD risk factors is apparently a risk for new onset of diabetes mellitus [6], kidney dysfunction [7], cardiovascular diseases, and increased mortality [8-12].

The components of MetS, namely, the CVD risk factors, have been shown to actually cluster more frequently than to occur by chance, and the actual prevalence of clustering exceeded the predicted one by $1.3,3.0$ and 8.0 for 3,4 , and 5 clustering of CVD risk factors [13].
For such clustering of CVD risk factors in MetS, insulin resistance was initially believed to play a key role [14], but the roles of adipocytokines released from visceral adipose tissue have been increasingly emphasized $[15,16]$, and waist circumference has become essential for the diagnosis of MetS [1-4]. Furthermore, both inflammation [17] and oxidative stress [18] have been implicated in the pathogenesis of MetS.

In our previous study [19], new onset of MetS was determined as new clustering of 3 or more CVD risk factors during the followup of 5 years in the general population. In this study, we studied the reversal rate from clustering of CVD risk factors during the same followup period. The rate of new clustering and its reversal would give us a clue to estimate the dynamic aspects of clustering or MetS. The role of each CVD risk factor on clustering and its reversal were also evaluated. 


\section{Methods}

2.1. Study Subjects. This community-based, observational cohort study was based on data of annual health examinations at the Niigata Health Foundation (Niigata, Japan). The examination is supported by the local government, is available to residents over 20 years of age, and is especially recommended for those without current medication. The examination consists of a detailed medical history: physical examination, blood examination including blood cell count and biochemical markers, chest X-ray, and a 12-lead ECG. This report included 35,534 subjects who received the examination both in 1996 as the baseline examination and 5 years later.

2.2. Definition of Clustering. Because of a lack of data of waist circumference, we defined clustering when subjects had at least 3 of the following CVD risk factors: (1) elevated body mass index (BMI) $\geq 25 \mathrm{Kg} / \mathrm{m}^{2}$, (2) elevated systolic $(\geq 130 \mathrm{~mm} \mathrm{Hg})$ and/or diastolic blood pressure $(\geq 85 \mathrm{~mm}$ $\mathrm{Hg})$, (3) elevated triglycerides ( $\geq 150 \mathrm{mg} / \mathrm{dL})$, (4) low highdensity lipoprotein (HDL) cholesterol $(\leq 40 \mathrm{mg} / \mathrm{dL}$ in men, $\leq 50 \mathrm{mg} / \mathrm{dL}$ in women), and (5) elevated fasting blood glucose $(F B G) \geq 100 \mathrm{mg} / \mathrm{dL}$. The subjects who were under therapy for hypertension, diabetes mellitus, and high TG were considered to have these items.

BMI was calculated by dividing the body weight in kilograms by the square of the height in meters, and this was used instead of waist circumference which was not available in our database at that time. Because of the differences in BMI between Japanese and Western populations, values $\geq 25 \mathrm{~kg} / \mathrm{m}^{2}$ were considered elevated in contrast to $\geq 30 \mathrm{~kg} / \mathrm{m}^{2}$ as in Western populations according to criteria of the Japan Society for the Study of Obesity [20-22].

2.3. Data Analysis. The baseline characteristics between the subjects who had clustering of CVD risk factors versus nonclustering was compared. Then, the reversal rates of clustering to 2 or less CVD risk factors were determined. The risk of age, gender, each CVD risk factor, and the number of clustered CVD risk factors regarding the reversal rate were determined.

Comparisons were undertaken by the unpaired $t$-test for continuous variables which were expressed as mean \pm SD and the $X^{2}$ test for categorical variables. Hazard ratios and 95\% CIs were calculated from the Cox proportional-hazard models. Cox models were adjusted for age as a continuous value and for sex to evaluate the contribution of each CVD risk factor and their combinations in the baseline data. All statistical analyses were performed with SPSS, version 12.0 (SPSS Inc, Chicago, Ill).

Two-sided values of $P$ at .05 were considered statistically significant. The authors had full access to and take full responsibility for the integrity of the data. All authors have read and approved the manuscript as written.

\section{Results}

3.1. Baseline Characteristics of Study Subjects. The baseline characteristics of the subjects are shown in Table 1. The mean age was $59.4 \pm 10.0$ years, and $67.9 \%$ of the subjects were women. The prevalence of each CVD risk factor, item of MetS, was $20.6 \%, 53.1 \%, 12.6 \%, 18.7 \%$, and $21.1 \%$ for obesity, elevated blood pressure, low HDL cholesterol, high TG, and abnormal FBG, respectively. Clinical hypertension ( $\geq 140 \mathrm{~mm} \mathrm{Hg}$ in systolic and/or $\geq 90 \mathrm{~mm} \mathrm{Hg}$ in diastolic) was present in $20 \%$ and antihypertensive treatment was administered to $14.0 \%$. Diabetes was found in $12 \%$, and $2.4 \%$ were under treatment. Clustering of CVD risk factors was present in 4,911 subjects $(13.8 \%)$ who were older $(P<.001)$ and had elevated BMI, blood pressure, TG and FBG and decreased HDL compared to those without clustering (Table 1).

3.2. Reversal Rate of Clustering. During the follow-up of exactly 5 years, 1,929 subjects among 4,911 subjects who had clustering of CVD risk factors at the baseline study no longer had clustering, and the reversal rate was found in $39.4 \%$.

The reversal rate of each CVD risk factoring was $41.0 \%$, $30.4 \%, 65.2 \%, 37.1 \%$, and $37.1 \%$ for BMI, blood pressure, TG, FBG, and HDL, respectively, in the subjects with a reversal, while in those without a reversal, a reversal was found only in HDL (15.2\%) and TG (0.9\%). Concerning other items, there was a tendency towards an increase by $0.6 \%, 0.7 \%$, and $16.7 \%$ for BMI, blood pressure, and FBG levels, respectively.

3.3. Predictors of Reversal of Clustering of CVD Risk Factors. At the baseline study, obesity, elevated blood pressure, and FBG were found less often in the subjects with a reversal of clustering of CVD risk factors in comparison with those without a reversal: $58.2 \%$ versus $73.9 \%(P<.001), 89.5 \%$ versus $91.4 \%(P<.03)$, and $54.8 \%$ versus $59.1 \%(P<.03)$, respectively, and others were comparable (Table 2 ).

A reversal of clustering was found more often in males than females: $42.3 \%$ versus $37.5 \%$ (hazard ratio $=1.31$, 1.15 1.50), but age dependency was not observed. Among CVD risk factors, obesity (BMI $\geq 25 \mathrm{~kg} / \mathrm{m}^{2}$ ) was associated with the least likelihood of reversal of clustering compared with the others (hazard ratio $=0.275$ for BMI versus $0.411,0.483$, 0.416 , and 0.515 for elevated blood pressure, triglycerides, FBG, and reduced HDL cholesterol, resp.) (Table 3).

In the subjects with a reversal of clustering, 3,4 , and 5 risk factors were found in $84.0 \%, 14.9 \%$, and $1.1 \%$ while in those without a reversal, they were found in $66.8 \%, 27.4 \%$, and $5.8 \%$, respectively, and these differences were significant $(P<.001)$. Fewer numbers of risk factors were found in the subjects with a reversal (Table 2). As the number of the risk factors increased, the reversal rate of clustering of CVD risk factors declined from $44.8 \%$ for $3,26.0 \%$ for 4 , and $12.8 \%$ for 5 CVD risk factors, and the hazard ratio for a reversal decreased (Table 3 ).

\section{Discussion}

At the baseline study, 4,911 persons (13.8\%) had clustering of CVD risk factors $\geq 3$, and at the followup 5 years later, 1,929 no longer had clustering and the reversal rate was $39.4 \%$. 
TABLE 1: Baseline characteristics of subjects with $(\geq 3)$ and without clustering (0-2) of CVD risk factors.

\begin{tabular}{lccc}
\hline & All subjects $(n=35,534)$ & Without clustering $(n=30,623)$ & With clustering $(n=4,911)$ \\
\hline Male $(\%)$ & 32.1 & 32.2 & 32.1 \\
Age (years) & $59.4 \pm 10.0$ & $59.1 \pm 10.0$ & $61.7 \pm 9.0^{*}$ \\
BMI $\left(\geq 25 \mathrm{~kg} / \mathrm{m}^{2}\right)$ & $22.8 \pm 2.9$ & $22.4 \pm 2.6$ & $25.7 \pm 2.8^{*}$ \\
Blood pressure $(\mathrm{mmHg})$ & & & \\
$\quad$ Systolic $(\geq 130 \mathrm{mmHg})$ & $128.7 \pm 17.3$ & $126.9 \pm 16.9$ & $140.5 \pm 14.9^{*}$ \\
Diastolic $(\geq 85 \mathrm{mmHg})$ & $77.4 \pm 10.7$ & $76.4 \pm 10.5$ & $83.3 \pm 9.8^{*}$ \\
HDL cholesterol $(\mathrm{mg} / \mathrm{dl})$ & & & \\
Men $(\leq 40 \mathrm{mg} / \mathrm{dL})$ & $60.4 \pm 15.2$ & $62.3 \pm 5.5$ & $49.9 \pm 13.8^{*}$ \\
Women $(\leq 50 \mathrm{mg} / \mathrm{dL})$ & $64.9 \pm 14.6$ & $66.6 \pm 14.5$ & $51.5 \pm 13.0^{*}$ \\
Triglyceride $(\geq 150 \mathrm{mg} / \mathrm{dl})$ & $100.8 \pm 65.8$ & $90.1 \pm 48.0$ & $167.7 \pm 108.6^{*}$ \\
FBG $(\geq 100 \mathrm{mg} / \mathrm{dL})$ & $93.2 \pm 14.0$ & $91.7 \pm 12.1$ & $102.9 \pm 19.7^{*}$ \\
\hline
\end{tabular}

BMI: Body mass index. HDL cholesterol: High-density lipoprotein cholesterol. FBG: Fasting blood glucose.

TABLE 2: Comparisons of basal characteristics between the entire subjects and those with and without reversal of clustering of CVD risk factors.

\begin{tabular}{|c|c|c|c|c|}
\hline Characteristics & All 4911 & With reversal $(n=1929)$ & No reversal $(n=2982)$ & $P$ value \\
\hline \multicolumn{5}{|l|}{ Risk factor (\%) } \\
\hline Obesity & 67.7 & 58.2 & 73.9 & $<.001$ \\
\hline Elevated blood pressure & 90.7 & 89.5 & 91.4 & .03 \\
\hline Low HDL cholesterol & 47.9 & 47.2 & 48.4 & .413 \\
\hline Elevated triglycerides & 66.6 & 67.3 & 66.1 & .369 \\
\hline Impaired glucose tolerance & 57.4 & 54.8 & 59.1 & .003 \\
\hline \multicolumn{5}{|l|}{ Number of risk factors } \\
\hline 3 & 73.6 & 84.0 & 66.8 & $<.001$ \\
\hline 4 & 22.5 & 14.9 & 27.4 & $<.001$ \\
\hline 5 & 4.0 & 1.1 & 5.8 & $<.001$ \\
\hline
\end{tabular}

TABLE 3: Multivariate analysis of hazard risks concerning reverse clustering of CVD risk factors after 5 years.

\begin{tabular}{lcc}
\hline Risk factor & HR $(95 \%$ CI $)$ & $P$ value \\
\hline Risk factor & $0.275(0.233-0.323)$ & $<.001$ \\
Obesity & $0.411(0.328-0.516)$ & $<.001$ \\
Elevated blood pressure & $0.515(0.439-0.603)$ & $<.001$ \\
Low HDL cholesterol & $0.483(0.41-0.569)$ & $<.001$ \\
Elevated triglycerides & $0.416(0.353-0.489)$ & $<.001$ \\
Impaired glucose tolerance & & \\
\hline
\end{tabular}

HR: Hazard ratio.

The subjects with a reversal of clustering had lower BMI, lower blood pressure, lower TG, and lower FBG $(P<.001)$. Higher HDL was associated with a reversal only in women $(P<.006)$. As the number of CVD risk factors increased, the reversal became less likely and BMI was the least associated with a reversal.

For the diagnosis of MetS, many types of criteria have been proposed from several organizations [1-5]. Waist circumference has been used in most criteria except for that of the American Association of Clinical Endocrinologists (AACE) which is using BMI for the diagnosis of obesity [5]. Using these criteria, the prevalence of MetS has been reported in many studies, but the incidence or reversal of MetS has been scarcely reported.

In the Framingham Study, multimarkers were evaluated to investigate their effects on the incidence of MetS. Two hundred eighty-two of 1,473 participants without prevalent MetS at baseline developed MetS during the mean followup of 2.9 years, and the incidence was $6.6 \%$ /year [23]. In another study, 75 of 184 hypertensive patients (41\%) initially free of MetS at baseline subsequently fulfilled the criteria for MetS during the 4 years of followup [24]. A higher calculated CHD risk $(P<.001)$ was found in those who developed MetS compared with those who did not.

Previously, we reported that MetS developed newly in $9.32 \%$ during the 5 year followup period in the general population [19] where MetS was diagnosed based on the BMI but not on waist circumference. Of note, obesity (BMI $\geq 25 \mathrm{Kg} / \mathrm{m}^{2}$ ) was associated with the highest hazard ratio in developing MetS or more clustering of CVD risk factors than other risk factors [19]. The importance of BMI would be compatible with the results of Fox et al. [25] who showed an association of obesity with newly developing MetS [25]. Furthermore, the present study showed that the reversal of once diagnosed clustering of CVD risk factors $\geq 3$ occurs frequently, 39.4\%, 5 years later, and BMI was associated with the least likelihood of reversal of clustering of CVD risk 
factors. For the reversal of clustering to occur, several factors must be included.

In the medical examination in the general population, the subjects are told the abnormal findings if any and advised to correct them. This is because early detection and the correction of abnormal findings are the main purpose of such an examination. Abnormalities may be corrected by self-control or by medical intervention, and this will partly explain the high reversal rate of clustering of CVD risk factors. Compared to other CVD risk factors, BMI would be difficult to treat by drugs, and, hence, it might be the least likely to be reversed.

Sampling variations or measurement errors may be another factor and may be mistaken as the reversal of clustering of CVD risk factors. These factors will affect both genders equally, but the reversal rate of clustering was different between men and women, suggesting that the reversal was not due to errors of samplings or measurements. Together with our previous study which revealed that 9.32\% of subjects without clustering at the baseline developed new clustering of $\geq 3$ CVD risk factors within 5 years [19], the prevalence will continue to increase in spite of the reversal of clustering by $39.4 \%$ from 13.8 to $16.4 \%$ after 5 years.

\section{Limitations}

We had some limitations in this study. First, this is a retrospective observational study and analysis was relatively limited. Next, we used BMI $\left(\geq 25 \mathrm{Kg} / \mathrm{m}^{2}\right)$ as the criterion of obesity. BMI reflects both visceral and subcutaneous obesity, and visceral obesity might be undetected by BMI. Clustering of $\geq 3$ risk factors as defined in the present study must be an approximation of the MetS which is defined using waist circumference [1-4]. However, BMI has been shown to play a role in developing new onset of atrial fibrillation [19] and chronic kidney disease [26] in addition to clustering of risk factors. Another limitation might be the fact that all subjects did not receive the same intervention in CVD risk factors but such would be not possible in this kind of a population-based study.

\section{Conclusion}

In conclusion, $39.4 \%$ of subjects with clustering of 3 or more CVD risk factors at the baseline study showed a reversal during the 5 years of followup. The reversal occurred more often in males, and the subjects with a reversal of clustering had milder levels of each risk factor and a smaller number of risk factors. Each risk factor affected the reversal, but BMI was associated with the least likelihood of a reversal.

\section{Acknowledgments}

The authors thank Mr. Oyanagi and the staff of the Niigata Health Foundation for assistance in collecting and managing the data. This work was partly supported by a grant from the Ministry of Health, Labor and Welfare, Japan, and the Niigata
Medical Association. Funding sources had no role in the way this study was designed or conducted.

\section{References}

[1] "Executive Summary of the Third Report of the National Cholesterol Education Program (NCEP) expert panel on detection, evaluation, and treatment of high blood cholesterol in adults (Adult Treatment Panel III)," Journal of the American Medical Association, vol. 285, no. 19, pp. 2486-2497, 2001.

[2] S. M. Grundy, J. I. Cleeman, S. R. Daniels et al., "Diagnosis and management of the metabolic syndrome: an American Heart Association/National Heart, Lung, and Blood Institute scientific statement," Circulation, vol. 112, no. 17, pp. 27352752, 2005.

[3] Committee for the Establishment of the Definition and Diagnostic Criteria of the Metabolic Syndrome in Japanese, "Metabolic syndrome-definition and diagnostic criteria in Japan," Journal of the Japan Society of International Medicine, vol. 94, pp. 749-809, 2005 (Japanese).

[4] Japan Atherosclerosis Society, Committee for Epidemiology and Clinical Management of Atherosclerosis; Metabolic syndrome, "Japan Atherosclerosis Society guidelines for prevention of atherosclerotic cardiovascular diseases," Journal of Atherosclerosis and Thrombosis, vol. 16, supplement, pp. 2630, 2009.

[5] D. Einhorn, G. M. Reaven, R. H. Cobin et al., "American College of Endocrinology position statement on the insulin resistance syndrome," Endocrine Practice, vol. 9, no. 3, pp. 237252, 2003.

[6] C. Lorenzo, M. Okoloise, K. Williams, M. P. Stern, and S. M. Haffner, "The metabolic syndrome as predictor of type 2 diabetes: the San Antonio Heart Study," Diabetes Care, vol. 26, no. 11, pp. 3153-3159, 2003.

[7] M. Kurella, J. C. Lo, and G. M. Chertow, "Metabolic syndrome and the risk for chronic kidney disease among nondiabetic adults," Journal of the American Society of Nephrology, vol. 16, no. 7, pp. 2134-2140, 2005.

[8] C. M. Alexander, P. B. Landsman, S. M. Teutsch, and S. M. Haffner, "NCEP-defined metabolic syndrome, diabetes, and prevalence of coronary heart disease among NHANES III participants age 50 years and older," Diabetes, vol. 52, no. 5, pp. 1210-1214, 2003.

[9] H.-M. Lakka, D. E. Laaksonen, T. A. Lakka et al., "The metabolic syndrome and total and cardiovascular disease mortality in middle-aged men," Journal of the American Medical Association, vol. 288, no. 21, pp. 2709-2716, 2002.

[10] E. S. Ford, "The metabolic syndrome and mortality from cardiovascular disease and all-causes: findings from the National Health and Nutrition Examination Survey II Mortality Study," Atherosclerosis, vol. 173, no. 2, pp. 309-314, 2004.

[11] J. K. Ninomiya, G. L'Italien, M. H. Criqui, J. L. Whyte, A. Gamst, and R. S. Chen, "Association of the metabolic syndrome with history of myocardial infarction and stroke in the Third National Health and Nutrition Examination Survey," Circulation, vol. 109, no. 1, pp. 42-46, 2004.

[12] H. Watanabe, N. Tanabe, T. Watanabe et al., "Metabolic syndrome and risk of development of atrial fibrillation: the Niigata Preventive Medicine Study," Circulation, vol. 117, no. 10, pp. 1255-1260, 2008.

[13] Y. Aizawa, H. Watanabe, M. M. Ramadan, Y. Usuda, T. Watanabe, and S. Sasaki, "Clustering trend of components of 
metabolic syndrome," International Journal of Cardiology, vol. 121, no. 1, pp. 117-118, 2007.

[14] J. B. Ruige, W. J. J. Assendelft, J. M. Dekker, P. J. Kostense, R. J. Heine, and L. M. Bouter, "Insulin and risk of cardiovascular disease: a meta-analysis," Circulation, vol. 97, no. 10, pp. 9961001, 1998.

[15] Y. Matsuzawa, "Pathophysiology and molecular mechanisms of visceral fat syndrome: the Japanese experience," Diabetes/Metabolism Reviews, vol. 13, no. 1, pp. 3-13, 1997.

[16] S. Fujioka, Y. Matsuzawa, K. Tokunaga, and S. Tarui, "Contribution of intra-abdominal fat accumulation to the impairment of glucose and lipid metabolism in human obesity," Metabolism, vol. 36, no. 1, pp. 54-59, 1987.

[17] P. M. Ridker, J. E. Buring, N. R. Cook, and N. Rifai, "Creactive protein, the metabolic syndrome, and risk of incident cardiovascular events: an 8-year follow-up of 14719 initially healthy American women," Circulation, vol. 107, no. 3, pp. 391-397, 2003.

[18] E. S. Ford, A. H. Mokdad, W. H. Giles, and D. W. Brown, "The metabolic syndrome and antioxidant concentrations: findings from the Third National Health and Nutrition Examination Survey," Diabetes, vol. 52, no. 9, pp. 2346-2352, 2003.

[19] A. Suzuki, K. Kosuge, O. Nanyu et al., "Five year study of cardiovascular risk factors in japanese people: implications concerning new onset of metabolic syndrome," Internal Medicine, vol. 49, no. 1, pp. 1-6, 2010.

[20] H. Sone, H. Ito, Y. Ohashi, Y. Akanuma, and N. Yamada, "Obesity and type 2 diabetes in Japanese patients," Lancet, vol. 361, no. 9351, p. 85, 2003.

[21] Examination Committee of Criteria for "Obesity Disease" in Japan, Japan Society for the Study of Obesity, "New criteria for "obesity disease" in Japan," Circulation Journal, vol. 66, pp. 987-992, 2002.

[22] S. Genuth, K. G. Alberti, P. Bennett et al., "Follow-up report on the diagnosis of diabetes mellitus," Diabetes Care, vol. 26, no. 11, pp. 3160-3167, 2003.

[23] E. Ingelsson, M. J. Pencina, G. H. Tofler et al., "Multimarker approach to evaluate the incidence of the metabolic syndrome and longitudinal changes in metabolic risk factors: the Framingham Offspring Study," Circulation, vol. 116, no. 9, pp. 984-992, 2007.

[24] H. S. Lim, G. Y. H. Lip, D. G. Beevers, and A. D. Blann, "Factors predicting the development of metabolic syndrome and type II diabetes against a background of hypertension," European Journal of Clinical Investigation, vol. 35, no. 5, pp. 324-329, 2005.

[25] C. S. Fox, J. M. Massaro, U. Hoffmann et al., "Abdominal visceral and subcutaneous adipose tissue compartments: association with metabolic risk factors in the Framingham Heart Study," Circulation, vol. 116, no. 1, pp. 39-48, 2007.

[26] H. Watanabe, H. Obata, T. Watanabe, S. Sasaki, K. Nagai, and Y. Aizawa, "Metabolic syndromeand risk of development of chronic kidney disease: the Niigata preventive medicine study," Diabetes Metabolism Research and Reviews, vol. 26, no. 1, pp. 26-32, 2009. 


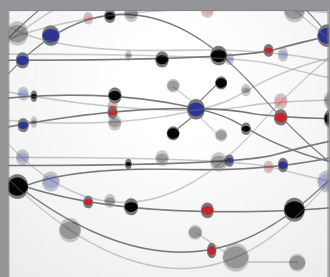

The Scientific World Journal
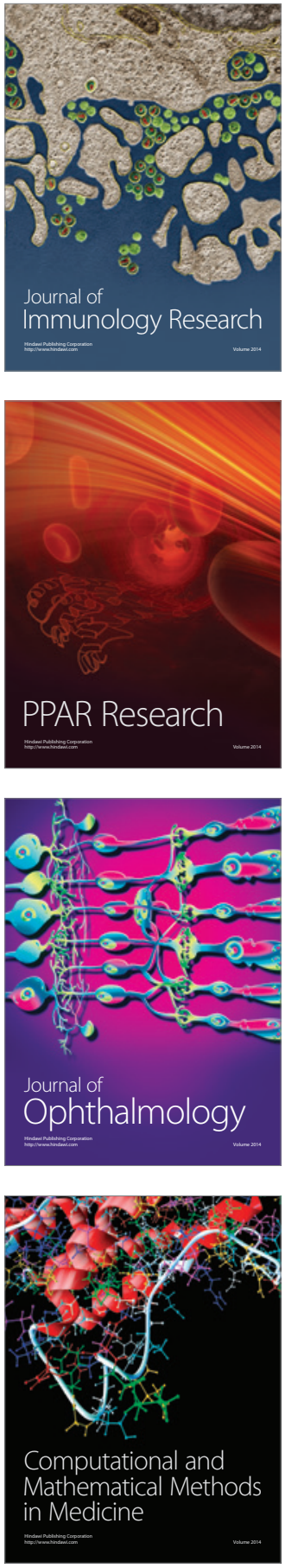

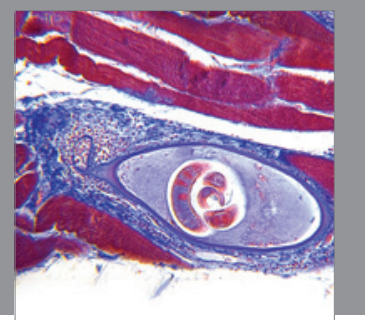

Gastroenterology

Research and Practice
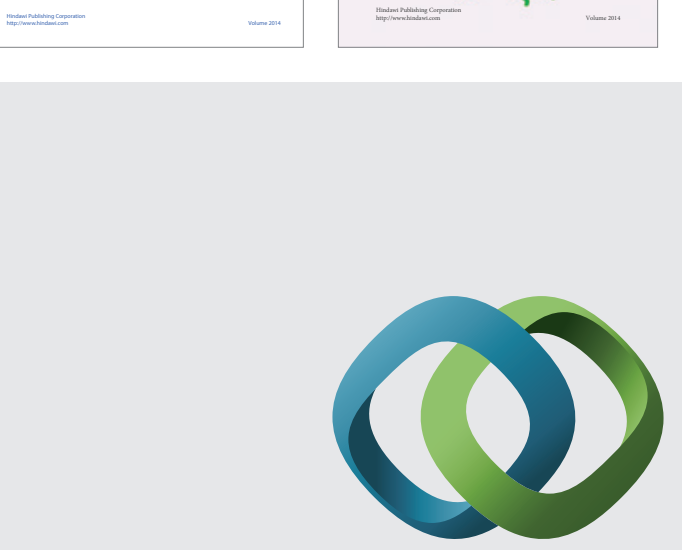

\section{Hindawi}

Submit your manuscripts at

http://www.hindawi.com
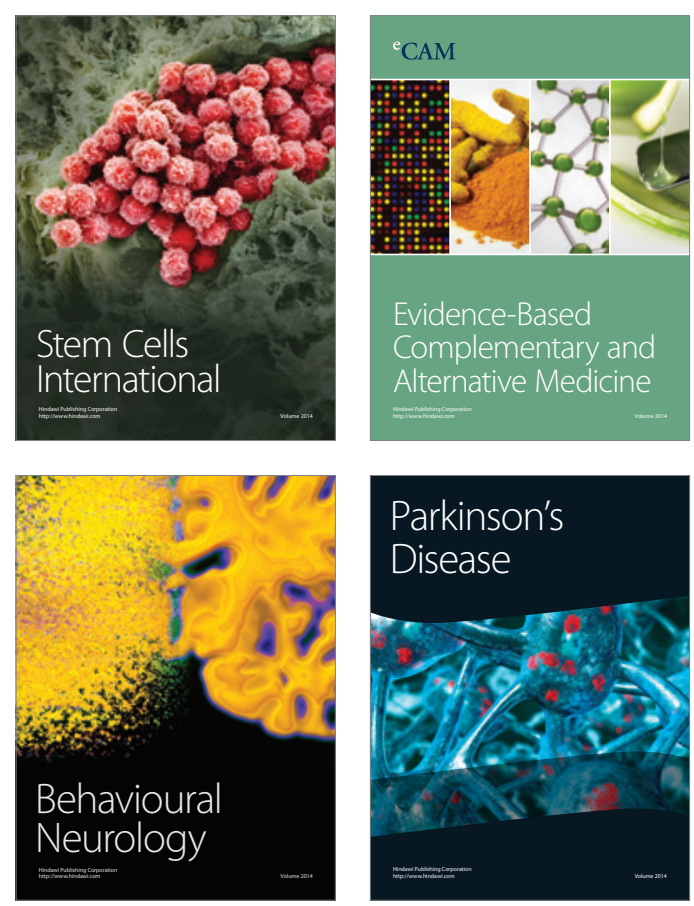

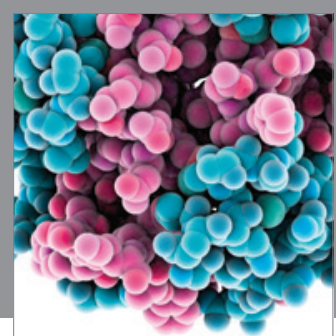

Journal of
Diabetes Research

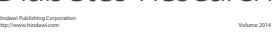

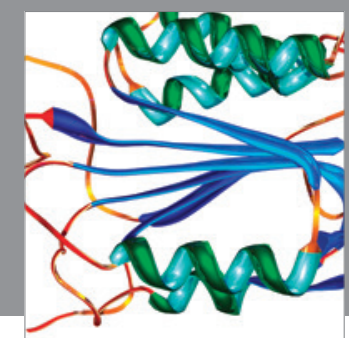

Disease Markers
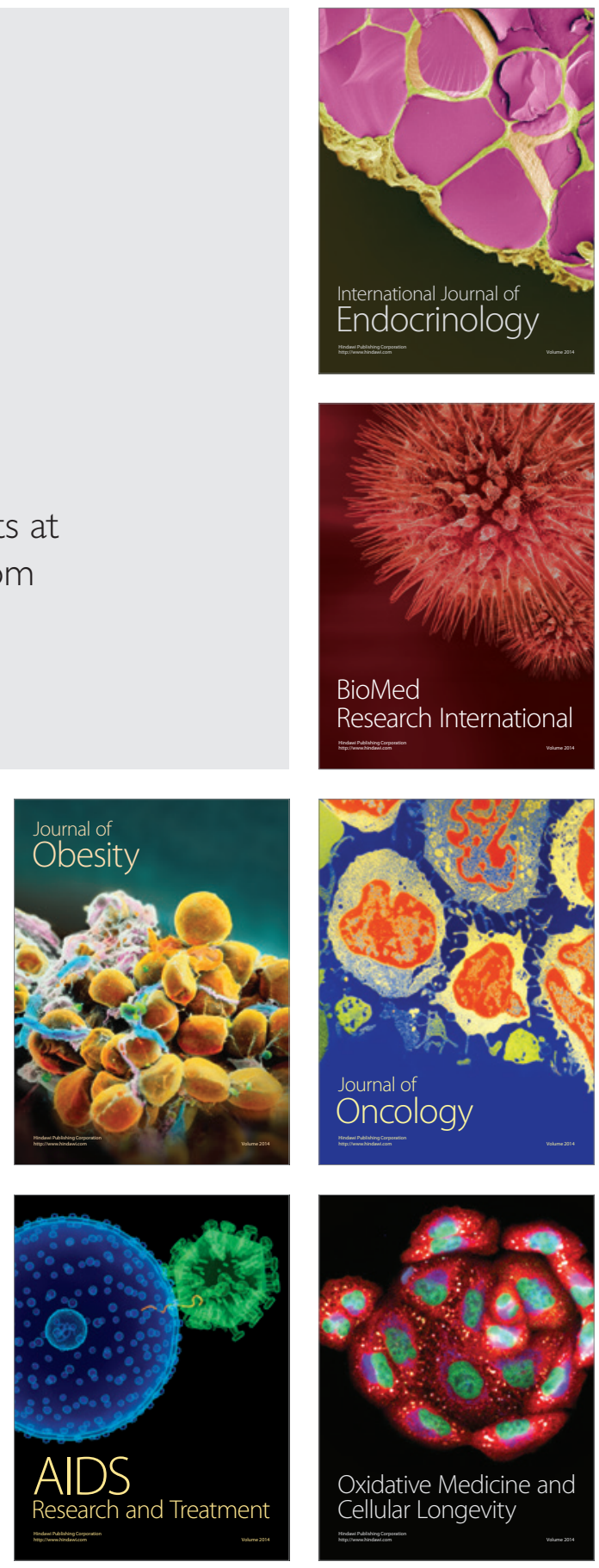